\title{
ACRL 2015 Conference
}

LISA MARTIN

University of Houston, Houston, Texas, United States

\section{ACRL 2015 Conference}

Oregon Convention Center, Portland, Oregon March 25 to 28, 2015

http://conference.acrl.org/

\section{Overview}

The Association of College and Research Libraries (ACRL), a division within the American Library Association, hosted its 75th anniversary conference in Portland, Oregon in 2015. The conference gathered together academic librarians from various fields under the theme of "Creating Sustainable Communities." The theme was echoed by the 11 program tags (which functioned as program tracks), including Teaching and Learning, Leadership and Management, and Professional and Staff Development. With such a wide variety of content represented, it wasn't difficult to find sessions relevant to the concerns of business librarians and libraries.

The conference included three keynote speakers along with a variety of program sessions, roundtables, workshops, poster sessions, etc. The keynote speakers were G. Willow Wilson, creator of comic-book superhero Kamala Khan; Jad Abumrad, host of the public radio program Radiolab, and Harvard professor and internet activist Lawrence Lessig. Attendees received access to the Virtual Conference (including the keynote speakers) for a year following the conference, and papers from the conference proceedings are freely available (Mueller, ed., 2015). What follows is a write-up of a selection of sessions from the conference which touch on areas of interest for business libraries, from appreciative inquiry to e-book collection development to managing organizational change.

\section{Workshop: Appreciative I nquiry}

Janet Cottrell, Director of Academic Resources and the Library at Champlain College, and Lindsay Godwin, Associate Professor at the Stiller School of Business at Champlain College, hosted "A Practical Approach to Appreciative Inquiry in Action: Be the change you want to see in your library." This three-hour workshop concentrated on creating tools for attendees to take away for use at their own institutions. Appreciative Inquiry, as defined by Cottrell and Godwin, states that "the actions I take affect the outcomes I experience" and is both a philosophy and a methodology. The workshop defined areas of focus, gave attendees techniques to use (primarily in the form of reframed questions such as "what do you want more of, not less" and "what do you want to support, not weaken"), and offered resources for further research. The speakers provided examples of Appreciative Inquiry in use during hiring (several innovative ideas were presented, including leaving the candidate pool open for management at the University of Houston, Immartin3@uh.edu. 
as long as possible instead of cutting candidates as quickly as possible) and change management (one example was the reorganization of a division at the college which involved collaborative discussions for more collective change). Overall, the workshop focused on practical ways to use appreciative inquiry in everyday life as a useful tool to manage decision-making and change.

\section{Session: Inclusive Culture}

"You Belong Here: The importance of cultivating an inclusive organizational culture" was presented by four librarians from Auburn University (Jaena Alabi, Bridget Farrell, Claudine Jenda, and Pambanisha Whaley). Topics covered included mentoring, racial microaggressions, impostor syndrome, and burnout. Not only are these topics pertinent to our users, many of whom are interested in learning about and researching social inclusion topics like these, they are also pertinent to our libraries and business schools as divisions within broader organizations. The four speakers put together a publicly available resources list (available from the link to the session on the scheduling page) that includes suggested readings and places to stay active on these topics. Racial microaggressions, presented by Jaena Alabi, was defined using Sue et al.'s definition: "brief, everyday exchanges that send denigrating messages to people of color because they belong to a racial minority group" (Sue et al., 2007). Alabi’s continuing research on what microaggressions look like in libraries and on academic campuses is important to increase awareness of the impact of these actions on librarians of color. Another topic, impostor syndrome, was presented as a set of negative feelings about oneself (especially when "oneself” is young, female, and/or on the tenure track) which can lead to self-sabotage and requires careful management, as detailed in a paper published in College and Research Libraries (Clark, Vardeman, and Barba, 2014). Overall, the session was a critical explanation of four areas where inclusion can falter and where those involved in creating organizational culture need to be aware.

\section{Session: Sustainability}

A session representing a diverse exploration of the librarianship field was "Sustainability across the Academic Library: Best practices, initiatives, and solutions in teaching, learning, and scholarship." Uniting under the book that they had put together on sustainability in the library (Jankowska, ed., 2014), the nine speakers addressed the topic in a variety of ways. One of the ways focused on the local: eco-composition, the theory that place has an effect on writing, was the topic of the first speakers. Specifically, they talked about how local information can be incorporated into writing exercises for composition students. The speakers discussed the extent to which local information is highly decentralized and community-based - such that there have to be stakeholders who are interested enough to create it - and how such information can be difficult to find or cite in an academic paradigm. All of these are concerns long familiar to business librarians searching for local business information. Another speaker likely to be of interest to those in business libraries spoke about sustainability in the context of triple bottom line accounting. The "triple" in triple bottom line accounting refers to "people, planet, and profit," and the speaker explained that while triple bottom line accounting is in use in some 
academic institutions, both libraries and business schools can make more mindful use of the method. Specific suggestions from the speaker include development of staff incentive programs, measurement and reporting on the organization's community impact, development of space audits, use of electricity saving measures, execution of HVAC upgrades, and working to do business with green and fair trade vendors. Though this session had a number of speakers, the myriad of perspectives on the topic of sustainability made the information useful for a variety of librarians.

\section{Contributed Papers Session: E-book usage}

Three papers covering e-book usage and collection trends were presented in a contributed papers session (the papers are available through the conference proceedings). Sarah Tudesco, Julie Linden, and Angela Sidman from Yale presented "Ebrary on the Radar: Some Unexpected Truths about Usage," which discussed the e-book package, Ebrary Academic Complete and how to assess usage in a package where titles change on a regular, but what had previously not been an always predictable, basis. The Yale speakers had excellent longitudinal data for their assessment of the package, as they had subscribed since the package's inception, which resulted in over 12 years of available data. They found, among other results, that e-books in the social sciences (including business) received much lower usage versus e-books in areas such as music or medicine. "e-Book Showdown: Evaluating Academic e-Book Platforms from a User Perspective" was the second paper presented, coming from San Jose State's Ann Agee and Christina Mune. This project evaluated e-book accessibility for 16 of the major e-book platforms. The final evaluation is online (Mune and Agee, 2014) and is well worth reading for more details about the metrics used and which vendors performed well. Kendall Hobbs and Diane Klare from Wesleyan University presented "Exploring the Student E-Book Experience" as the final paper of the session. The authors presented data from a four-year study in which every year they had asked students about their experiences with e-books. Key highlights include the fact that $86 \%$ of students over the years preferred print books to e-books, but students often use print books and e-books in tandem (using the e-book to search for what they need but then checking out the print book to read it); that students typically prefer a PDF over other formats; and that (unsurprisingly) students prefer consistency across platforms. One major takeaway is that students decided to purchase edited multi-chapter books electronically but single author titles in print. Overall, the papers presented a lively and helpful set of ways to evaluate e-books for our collections.

\section{Contributed Papers Session: Organizational Culture}

Another contributed papers session covered organizational culture (the three papers are also available through the conference proceedings). Erin Smith, Jamie Kohler, and John Garrison from Westminster College spoke about "Embracing Evolution: A Collaborative Approach to Library Organizational Change" in the first paper presented. Like many of our libraries, Westminster experienced a wave in retirements (in their case, they lost 4 of their 9 staff) and had to come up with a new way to organize the library as staff left. Because no jobs were at stake, they found it helpful to look at the duties everyone in the library performed, how 
relevant they were to what the needs of the modern college were, and what preferences existed among staff for which duties (for example, they moved a public-facing staff member to a non-public-facing role per the staffer's request). The second paper, from Rebecca Miller at Virginia Tech, entitled "Individual Adaptation: Interdisciplinary Perspectives on Personal Identity and Learning during Organizational Change," covered business and psychology research on personal experiences of organizational change. Key ideas put forward include a call to respect the individual, that a person's identity plays an important role in their growth and perception of change, and that successful change is participatory. A number of key researchers and theorists were cited by Miller, and it is well worth reviewing her paper in the conference proceedings to understand more about this topic. The third and final paper, "Dare to Perform: Using Organizational Competencies to Manage Job Performance" came from Lorelei Rutledge, Sarah LeMire, and Alfred Mowdood who were then all at the University of Utah (LeMire is now at Texas A\&M). At Utah, the Reference and Information Services division used competency-based hiring and evaluation as a way to make the members of their organization "post-job" (meaning that the organization looks to hire someone who fits initial skills and requirements but who can, as needed, develop specific competencies for new requirements). Though hiring was a major component of the presentation, the speakers also focused on the need for continued professional growth and using competencies to motivate more experienced librarians to continue their growth as well. All three contributed papers from this session provided an intriguing look at the ways in which individual libraries are tackling organizational culture and the changing environment in which we operate.

ACRL's biennial conference offers a wide variety of perspectives on changes in the academic library field. From collections to instruction to leadership, there are opportunities to hear from established voices and new librarians sometimes all at the same session. Though not specifically focused on business librarians, ACRL offers much for business librarians to learn. It also offers excellent opportunities for networking, as demonstrated by the informal meet-up of business librarians one rainy evening, and provides a chance to learn how the broader academic library world is reacting to concerns which business libraries also face, in one form or another. ACRL 2015 was no exception.

\section{References}

Clark, Melanie, Vardeman, Kimberly, and Barba, Shelley. 2014. Perceived Inadequacy: A Study of the Imposter Phenomenon among College and Research Librarians. College and Research Libraries 75(3), 255-271. Retrieved from: http://crl.acrl.org/content/75/3/255.

Jankowska, Maria, ed. 2014. Focus on Educating for Sustainability: Toolkit for Academic Libraries. Sacramento, California: Library Juice Press.

Mueller, Dawn, ed. 2015. ACRL 2015 Conference Proceedings. Association of College and Research Libraries, American Library Association. Retrieved from: http://www.ala.org/acrl/sites/ala.org.acrl /files/content/conferences/confsandprec onfs/2015/ACRL2015 A.pdf.

Mune, Christina and Ann Agee. 2014. eBook Accessibility Project. San Jose State 
Ticker: The Academic Business Librarianship Review, 1:2 (2016)

(C) 2016 Lisa Martin

University. Retrieved from:

http://libguides.sjsu.edu/eap.

Sue, Derald, Capodilupo, Christina, Torino,

Gina, Bucceri, Jennifer, Holder Aisha, Nadal, Kevin, and Esquilin, Marta. 2007.

Racial microaggressions in everyday life:

implications for clinical practice. American

Psychologist 62(4), 271-286. Retrieved from:

http://psycnet.apa.org/journals/amp/62

L4/271/. 